\title{
Hypercaloric cafeteria-like diet induced UCP3 gene expression in skeletal muscle is impaired by hypothyroidism
}

M.A. Christoffolete ${ }^{1}$ and A.S. Moriscot ${ }^{2}$
Departamentos de ${ }^{1}$ Fisiologia e Biofísica and

${ }^{2}$ Histologia e Embriologia, Instituto de Ciências Biomédicas,

Universidade de São Paulo, São Paulo, SP, Brasil

\section{Correspondence}

A.S. Moriscot

Departamento de Histologia e

Embriologia, ICB, USP

Av. Lineu Prestes, 1524

05508-900 São Paulo, SP

Brasil

E-mail: moriscot@usp.br

Research partially supported by FAPESP (Nos. 97/0650-0 and 98/10498-4.

Received May 6, 2003 Accepted February 10, 2004

\begin{abstract}
The uncoupling protein UCP3 belongs to a family of mitochondrial carriers located in the inner mitochondrial membrane of certain cell types. It is expressed almost exclusively at high levels in skeletal muscle and its physiological role has not been fully determined in this tissue. In the present study we have addressed the possible interaction between a hypercaloric diet and thyroid hormone $\left(\mathrm{T}_{3}\right)$, which are strong stimulators of UCP3 gene expression in skeletal muscle. Male Wistar rats weighing $180 \pm 20 \mathrm{~g}$ were rendered hypothyroid by thyroidectomy and the addition of methimazole $(0.05 \% ; \mathrm{w} / \mathrm{v})$ to drinking water after surgery. The rats were fed a hypercaloric cafeteria diet (68\% carbohydrates, $13 \%$ protein and $18 \%$ lipids) for 10 days and sacrificed by decapitation. Subsequently, the gastrocnemius muscle was dissected, total RNA was isolated with Trizol ${ }^{\mathrm{TM}}$ and UCP3 gene expression was determined by Northern blotting using a specific probe. Statistical analysis was performed by one-way analysis of variance (ANOVA) followed by the Student-Newman-Keuls posttest. Skeletal muscle UCP3 gene expression was decreased by $60 \%$ in hypothyroid rats and UCP3 mRNA expression was increased $70 \%$ in euthyroid cafeteria-fed rats compared to euthyroid chow-fed animals, confirming previous studies. Interestingly, the cafeteria diet was unable to stimulate UCP3 gene expression in hypothyroid animals ( $40 \%$ lower as compared to euthyroid cafeteria-fed animals). The results show that a hypercaloric diet is a strong stimulator of UCP3 gene expression in skeletal muscle and requires $T_{3}$ for an adequate action.
\end{abstract}

It is well recognized that food processing induces a basal heat production, which combined with other physiological processes, results in the so-called obligatory thermogenesis. In addition, food intake also triggers a regulated form of thermogenesis which takes place mainly in the brown adipose
Key words

- Thyroid hormone

- Hypothyroidism

- Hypercaloric diet

- Uncoupling protein

- UCP3 tissue (BAT) of small rodents and plays a key role in the control of energy balance, a process called diet-induced thermogenesis (DIT) $(1,2)$. Several studies have shown that BAT is capable of buffering excessive caloric intake by uncoupling mitochondria from ATP synthesis. This is possible due to an inner 
mitochondrial membrane protein called UCP1, which bypasses the mitochondrial proton gradient without ATP synthesis. The role of UCP1 (the first UCP cloned and identified) in energy dissipation has been confirmed in animals during starvation (3), in transgenic mice overexpressing UCP1 in white adipose tissue (4), and in animals with deficient UCP1 expression in BAT (4).

Other members of the UCP family are also considered to be possibly involved in DIT. Indeed, some studies have reported a correlation between UCP3 expression and increased oxygen consumption in skeletal muscle (5-8). Several studies have shown that UCP3 mRNA in muscle, heart and adipose tissue is up-regulated by increased plasma free fatty acid levels due to starvation in humans $(9,10)$, by a high lipid content $\operatorname{diet}(11)$ and by genetic/experimental diabetes in rodents (12). However, a rise in fatty acids is not required for $\mathrm{UCP} 3$ up-regulation in gastrocnemius muscle during starvation (13). In addition, hypothyroid animals on a high calorie/high lipid content diet were found to present increased oxygen consumption compared to hypothyroid animals on a regular diet (14). Since increased oxygen consumption cannot be achieved in BAT of hypothyroid animals, alternative sites have been suggested to be involved in energy balance control, such as skeletal muscle. In contrast, during fasting, a condition in which energy dissipation tends to decrease, UCP3 expression is up-regulated $(10,15)$ and acute physical activity (15), which promotes energy depletion, also appears to increase UCP3 gene expression.

In addition to the discrepant reports about the physiological role of UCP3 in skeletal muscle, the interactions of known UCP3 regulators are also poorly understood. For instance, thyroid hormone $\left(\mathrm{T}_{3}\right)$ and hypercaloric/lipidic diets are known to be strong stimulators of UCP3 gene expression (5,7,8, $16,17)$, yet it is not clear how such activators interact. Therefore, in the present study, the effect of $\mathrm{T}_{3}$ and a hypercaloric diet on UCP3 gene expression in skeletal muscle was addressed by feeding rats a cafeteria diet.

Experiments were performed on male Wistar rats weighing $180 \pm 20 \mathrm{~g}$, obtained from our breeding colony. Animals were maintained on a 12:12-h dark-light cycle at room temperature and, unless specified, had free access to standard chow and water. Surgical thyroidectomy was performed under light ether anesthesia and was followed by administration of $0.05 \%$ methimazole (Sigma, St. Louis, MO, USA) in drinking water. Each experimental group consisted of 2-3 animals per experiment.

The cafeteria diet is based on the products found in a typical American cafeteria, which are industrialized products with high caloric values. The macronutrient composition of the cafeteria diet was $68 \%$ carbohydrates, $13 \%$ protein and $18 \%$ lipids while the standard chow diet is composed of $80 \%$ carbohydrates, $19 \%$ protein and less than $1 \%$ lipids. The animals were placed in individual cages and food intake was monitored for 10 days. The weights of the diet components were determined individually the day before and the day after they were offered to the rats (prior to the beginning of the dark cycle), with the difference between weights corresponding to the amount of food eaten. Four groups were studied: I) euthyroid rats on a standard chow diet; II) hypothyroid rats on a standard chow diet; III) euthyroid rats on a cafeteria diet, and IV) hypothyroid rats on a cafeteria diet. At the end of each experiment the animals were sacrificed by decapitation and the gastrocnemius muscle was dissected, immediately frozen in liquid nitrogen and stored at $-70^{\circ} \mathrm{C}$. Total RNA was isolated by the Trizol ${ }^{\mathrm{TM}}$ method (Invitrogen) and transferred to a nylon membrane, and a $20-\mu \mathrm{g}$ amount was pre-hybridized with 0.5 M sodium phosphate, $\mathrm{pH} 6.8,7 \% \mathrm{SDS}, 1 \%$ BSA, $1 \mathrm{mM}$ EDTA, and $200 \mu \mathrm{g} / \mathrm{ml}$ salmon DNA for $4 \mathrm{~h}$ at $65^{\circ} \mathrm{C}$. Subsequently, the membrane was incubated with a specific 
probe (Genbank \#U92069) for UCP3 for 18 $\mathrm{h}$ and $18 \mathrm{~S}$ rRNA was used as internal control. The membrane was washed twice for 5 $\min$ in SSC $0.1 \mathrm{X}$ and $0.1 \% \mathrm{SDS}$ at $50^{\circ} \mathrm{C}$, and for $15 \mathrm{~min}$ in $\mathrm{SSC} 2 \mathrm{X}$ and $1 \% \operatorname{SDS} 1$ at $55^{\circ} \mathrm{C}$. Images were obtained with a STORM 840 instrument (Molecular Dynamics, Sunnyvale, CA, USA) and band densitometry was determined using the ImageQuant software (Molecular Dynamics). Data are reported as means \pm SEM. One-way analysis of variance (ANOVA) was used, followed by the Student-Newman-Keuls post-test. For all tests, $\mathrm{P}<0.05$ was considered statistically significant. For statistical analysis we used the GraphPad Instat Software (GraphPad Software Inc., San Diego, CA, USA).

Euthyroid animals submitted to the cafeteria diet increased their caloric intake by $\sim 1$.6-fold compared to euthyroid chow-fed animals. An increase in caloric intake by cafeteria-fed hypothyroid rats was also noted as compared to chow-fed hypothyroid animals (Figure 1). Despite the clear increase in caloric intake in the cafeteria-fed groups, the $\Delta$ body weight did not differ significantly between the chow and cafeteria groups ( $23 \pm$ $5.7 \mathrm{~g}$ euthyroid chow-fed, $31.8 \pm 2.8 \mathrm{~g}$ euthyroid cafeteria-fed, $-2.3 \pm 4 \mathrm{~g}$ hypothyroid chow-fed, and $-11 \pm 6.1 \mathrm{~g}$ hypothyroid cafeteria-fed rats).

The UCP3 gene expression was increased 1.7 -fold by the cafeteria diet in euthyroid animals compared to the euthyroid chow-fed group. Hypothyroidism induced a $\sim 60 \%$ reduction in UCP3 gene expression in chowfed animals. Interestingly, in cafeteria-fed animals, hypothyroidism also induced a $\sim 40 \%$ decrease in UCP3 gene expression (Figure 2A,B).

Our results confirm previous data in the literature showing that hypothyroidism decreases (16) while high lipid content diet increases (11) UCP3 mRNA levels in skeletal muscle. In the present study, the increase in UCP3 expression observed in euthyroid animals on the cafeteria diet was

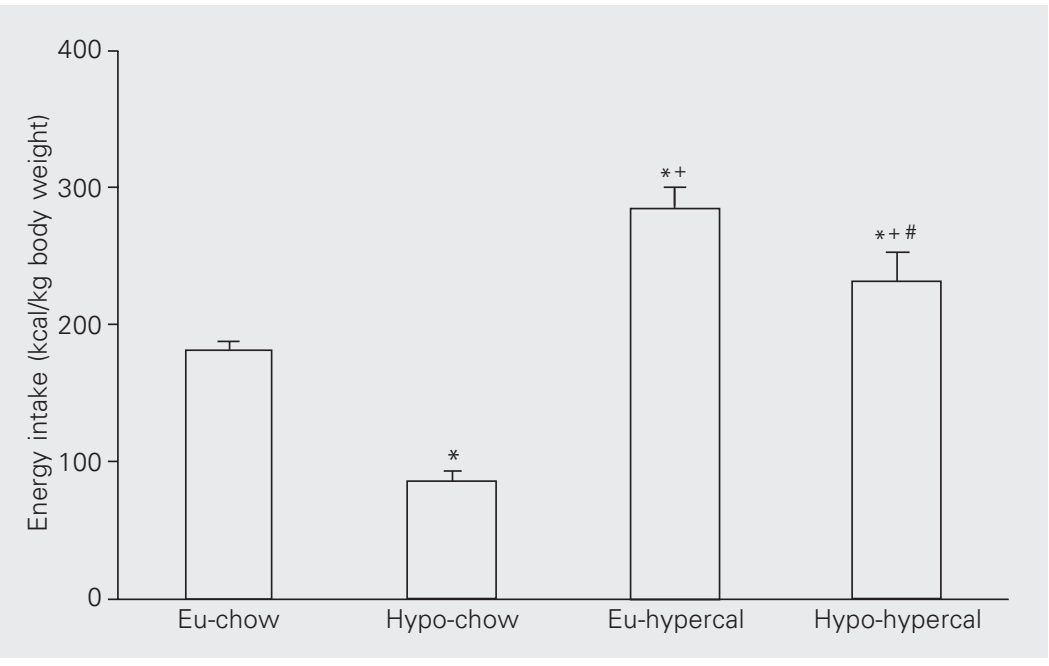

Figure 1. Daily energy intake (kcal/kg body weight) by euthyroid chow-fed (Eu-chow), hypothyroid chow-fed (Hypo-chow), euthyroid hypercaloric diet-fed (Eu-hypercal) and hypothyroid hypercaloric diet-fed (Hypo-hypercal) rats during the 10 days of the experiment. ${ }^{*} \mathrm{P}$ $<0.01$ vs Eu-chow, ${ }^{+} \mathrm{P}<0.01$ vs Hypo-chow, ${ }^{\#} \mathrm{P}<0.01$ vs Eu-hypercal (ANOVA followed by the Student-Newman-Keuls post-test).
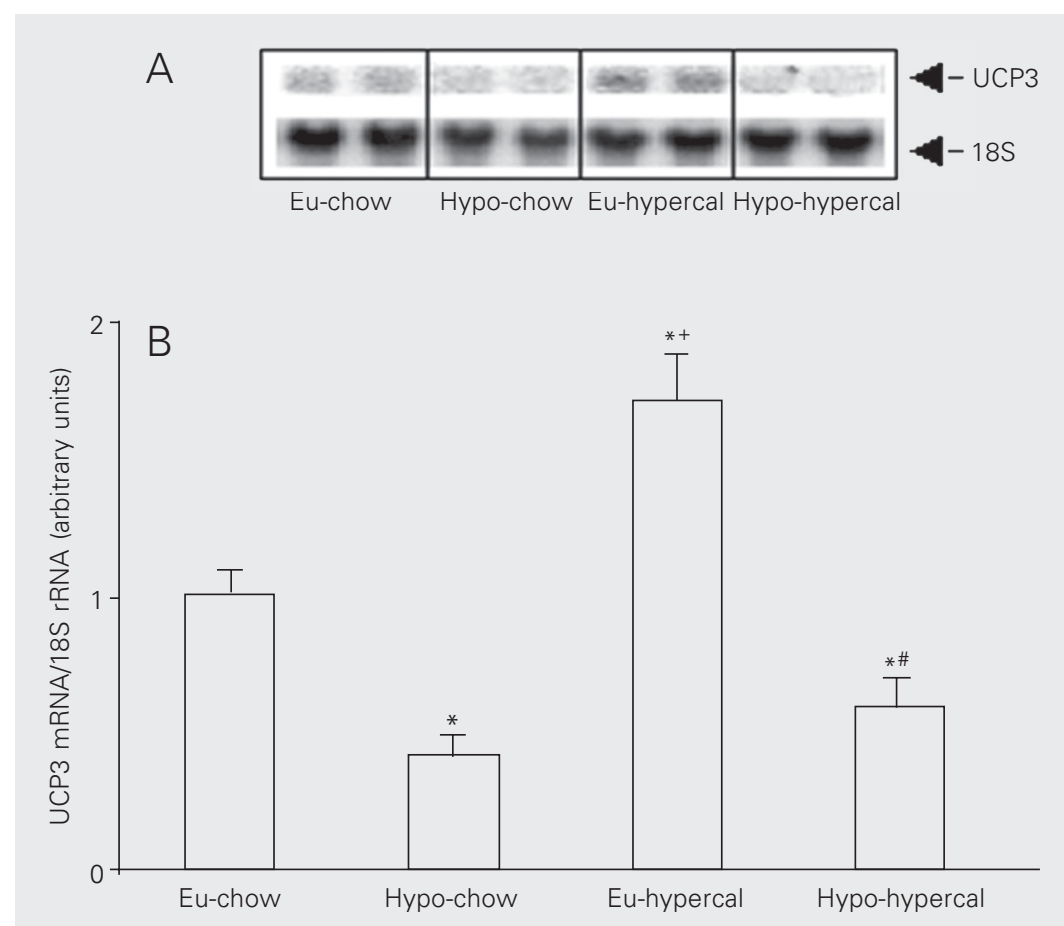

Figure 2. Abundance of mRNA/UCP3 in euthyroid chow-fed (Eu-chow), hypothyroid chowfed (Hypo-chow), euthyroid hypercaloric diet-fed (Eu-hypercal) and hypothyroid hypercaloric diet-fed (Hypo-hypercal) rats. A, Northern blot analysis of UCP3 mRNA levels and 18S rRNA in gastrocnemius muscle. $B$, Histogram representing the densitometry of the bands. Data are reported as arbitrary units of mRNA for UCP3/rRNA 18S. ${ }^{*} \mathrm{P}<0.05$ vs Eu-chow, $+P<0.05$ vs Hypo-chow, ${ }^{\#} P<0.05$ vs Eu-hypercal (ANOVA followed by the StudentNewman-Keuls post-test). 
minimized in hypothyroid animals receiving the same diet, showing that $T_{3}$ plays a key role in UCP3 gene responsiveness to a hypercaloric stimulus.

BAT, the major site of facultative thermogenesis in rodents, is not functional in hypothyroids rats (18). A previous study has shown that hypothyroid rats on a cafeteria diet increase their oxygen consumption compared to hypothyroid rats on a chow diet, probably due to DIT, suggesting that in the absence of functional BAT other unknown adaptive thermogenic mechanisms might be recruited in hypothyroid rats (14). It is reasonable to assume that skeletal muscle may be a natural alternative candidate for mediating DIT, possibly due to increased UCP3 expression. Our findings show that UCP3 gene expression was unchanged in hypothyroid rats submitted to a hypercaloric diet for 10 days. These data support the idea that alternative thermogenic mechanisms such as uncoupling by UCP2 may be activated, although the UCP2 gene has been shown to function similarly to the UCP3 gene under certain physiological conditions (10). In agreement with our observations (17), it has been suggested that an increase in UCP3 expression may not be the only factor re- sponsible for the $\mathrm{T}_{3}$-induced uncoupling effect. In addition, UCP3 knock-out mice do not develop obesity, with their weights being similar to those of wild-type mice (19). The role of UCP2 and UCP3 in adaptive thermogenesis, in addition to their ability to uncouple mitochondrial respiration, remain unclear. In fact, recent studies have proposed that the primary function of UCP2 and $\mathrm{UCP} 3$ is to act as regulators of reactive oxygen species production in the mitochondria, having a secondary effect on energy expenditure and, consequently, on body weight (20).

In vitro studies involving different skeletal muscle cell lines should be conducted in the future in order to provide further insight into the possible interactions between energetic substrate loading and $\mathrm{T}_{3}$ upon UCP3 gene expression and provide a better understanding of the physiological role of UCP3 in skeletal muscle.

\section{Acknowledgments}

The authors would like to acknowledge José Luiz dos Santos and Alessandra Crescenzi for excellent technical assistance.

\section{References}

1. Rothwell NJ \& Stock MJ (1979). A role for brown adipose tissue in diet-induced thermogenesis. Nature, 281: 31-35.

2. Dulloo AG, Samec S \& Seydoux J (2001). Uncoupling protein 3 and fatty acid metabolism. Biochemical Society Transactions, 29: 785791.

3. Himms-Hagen J (1990). Brown adipose tissue thermogenesis: interdisciplinary studies. FASEB Journal, 4: 2890-2898.

4. Kopecky J, Clarke G, Enerback S, Spiegelman B \& Kozak LP (1995). Expression of the mitochondrial uncoupling protein gene from the aP2 gene promoter prevents genetic obesity. Journal of Clinical Investigation, 96: 2914-2923.

5. Lanni A, Beneduce L, Lombardi A, Moreno M, Boss O, Muzzin P, Giacobino JP \& Goglia F (1999). Expression of uncoupling protein-3 and mitochondrial activity in the transition from hypothyroid to hyperthyroid state in rat skeletal muscle. FEBS Letters, 444: 250254.
6. Jucker BM, Dufour S, Ren J, Cao X, Previs SF, Underhill B, Cadman KS \& Shulman GI (2000). Assessment of mitochondrial energy coupling in vivo by 13C/31P NMR. Proceedings of the National Academy of Sciences, USA, 97: 6880-6884.

7. de Lange P, Lanni A, Beneduce L, Moreno M, Lombardi A, Silvestri E \& Goglia $F$ (2001). Uncoupling protein-3 is a molecular determinant for the regulation of resting metabolic rate by thyroid hormone. Endocrinology, 142: 3414-3420.

8. Schrauwen P, Saris WH \& Hesselink MK (2001). An alternative function for human uncoupling protein 3: protection of mitochondria against accumulation of nonesterified fatty acids inside the mitochondrial matrix. FASEB Journal, 15: 2497-2502.

9. Millet L, Vidal H, Andreelli F, Larrouy D, Riou JP, Ricquier D, Laville $M$ \& Langin D (1997). Increased uncoupling protein-2 and -3 mRNA expression during fasting in obese and lean humans. Journal of Clinical Investigation, 100: 2665-2670. 
10. Boss O, Samec S, Kuhne F, Bijlenga P, Assimacopoulos-Jeannet F, Seydoux J, Giacobino JP \& Muzzin P (1998). Uncoupling protein-3 expression in rodent skeletal muscle is modulated by food intake but not by changes in environmental temperature. Journal of Biological Chemistry, 273: 5-8.

11. Matsuda J, Hosoda K, Itoh H et al. (1997). Cloning of rat uncoupling protein-3 and uncoupling protein-2 cDNAs: their gene expression in rats fed high-fat diet. FEBS Letters, 418: 200-204.

12. Hidaka S, Kakuma $T$, Yoshimatsu H, Sakino H, Fukuchi S \& Sakata $T$ (1999). Streptozotocin treatment upregulates uncoupling protein 3 expression in the rat heart. Diabetes, 48: 430-435.

13. Samec S, Seydoux J \& Dulloo AG (1998). Interorgan signaling between adipose tissue metabolism and skeletal muscle uncoupling protein homologs: is there a role for circulating free fatty acids? Diabetes, 47: 1693-1698.

14. Curcio C, Lopes AM, Ribeiro MO, Francoso Jr OA, Carvalho SD, Lima FB, Bicudo JE \& Bianco AC (1999). Development of compensatory thermogenesis in response to overfeeding in hypothyroid rats. Endocrinology, 140: 3438-3443.

15. Zhou M, Lin BZ, Coughlin S, Vallega G \& Pilch PF (2000). UCP-3 expression in skeletal muscle: effects of exercise, hypoxia, and AMP-activated protein kinase. American Journal of Physiology, 279: E622-E629.

16. Gong DW, He Y, Karas M \& Reitman M (1997). Uncoupling protein3 is a mediator of thermogenesis regulated by thyroid hormone, beta3-adrenergic agonists, and leptin. Journal of Biological Chemistry, 272: 24129-24132.

17. Lebon V, Dufour S, Petersen KF, Ren J, Jucker BM, Slezak LA, Cline GW, Rothman DL \& Shulman GI (2001). Effect of triiodothyronine on mitochondrial energy coupling in human skeletal muscle. Journal of Clinical Investigation, 108: 733-737.

18. Silva JE \& Rabelo R (1997). Regulation of the uncoupling protein gene expression. European Journal of Endocrinology, 136: 251-264.

19. Vidal-Puig AJ, Grujic D, Zhang CY et al. (2000). Energy metabolism in uncoupling protein 3 gene knockout mice. Journal of Biological Chemistry, 275: 16258-16266.

20. Schrauwen P \& Hesselink M (2002). UCP2 and UCP3 in muscle controlling body metabolism. Journal of Experimental Biology, 205: 2275-2285. 